\title{
Psychiatric diagnosis as an ethical problem
}

\author{
E M Shackle Religious Education teacher, London
}

\section{Author's abstract}

Psychiatrists diagnose mental illness in patients against a climate of opinion in which the value of diagnosis is questioned and non-medical formulations of the problems of psychiatric patients are put forward. Nevertheless the classic diagnostic terminology shows no sign of disappearing. The patients may find that a psychiatric diagnostic label is a stigma and has bad consequences. They may also object to standard methods of treatment. Given this situation the right of the patient to a full explanation of the diagnosis and the rationale of the treatment offered seems to be incontrovertible. If this information were given to patients it would, in addition, help them to make sense out of their often puzzling experiences and indicate that fellow sufferers existed.

The title of this paper is plagiarised from Walter Reich's chapter of the same name in Psychiatric Ethics (1). His discussion concentrates on the ethical effects of misdiagnosis and the consequent exposure of persons so diagnosed to 'the harmful effects of diagnosis'. These effects, according to Reich 'include not only the loss of personal freedom and the subjection to noxious psychiatric environments and treatments, but also the possibility of life-long labelling $(2,3,4)$ as well as a variety of legal and social disadvantages ranging from declarations of non-responsibility in family and financial affairs to, under the most extreme circumstance, the deprivation of life' (5).

After reading this list it seems at least arguable that the harmful effects of diagnosis on those who are correctly diagnosed, such effects being largely due to institutionalised attitudes and not intrinsic to any postulated disease process, do in themselves pose certain ethical problems. This is not to say that these attitudes may not be capable of some justification. It is, however, hard to think of any diagnosis of physical illness that brings with it such stigmata as Reich lists. The newly-diagnosed mentally ill patient is in the position of the royal baby at the christening: the good fairy is there with her blessings and the bad fairy with

\section{Key words}

Right to know; diagnosis; stigma; cognitive needs. her curses. What has the good fairy got to offer on this occasion? At her best she can offer the patient some understanding of the condition and treatment both short and long-term that will alleviate the patient's suffering and bring about, in some cases, a cure or a change of heart. But she cannot do much to reduce the stigma that can accompany the former mental patient through life and is particularly crippling in the area of employment. The proximity of the bad fairy at the christening may well make both the undiagnosed mentally ill person, let alone many who have gone through this ritual, wonder whether the good effects of submission to the process outweigh the harmful effects in all or most cases.

Some of these considerations are crucial to the antipsychiatry movement. Much of the argument is devoted to an analysis of the harmful effects of institutionalised psychiatry (6), and much else to the beneficial effects of alternatives to conventional methods of treatment (7). What is not usually denied is that the phenomena whose presence were responsible for the diagnosis should be cause for concern.

The anti-psychiatry movement tends to argue that the process of diagnosis should be abolished altogether. Anthony Clare has made a brilliant and convincing defence of the practice in his Psychiatry in Dissent (8). He argues that no clinician can work in the absence of general concepts and laws. The attempt to see every individual and case as unique makes for zero understanding in the absence of a framework. Clare gives a detailed and fascinating exposition of the practice of psychiatric diagnosis. His general arguments apply even where therapists prefer to use a non-medical model: an acceptable formulation of the problem has to exist that is comprehensible to client, therapist, and colleague alike. (It is intriguing in this connection to see to what extent the literature of antipsychiatry does use in its argument the much-maligned classical diagnostic categories.)

If diagnosis or assessment is not abolished one task of the clinician is to maximise the good and minimise the bad effects that accrue to the patients as a result of the procedure. The most evident immediate effects of diagnosis to the patient who is hospitalised come under Reich's heading of exclusion and dehumanisation (9). The autobiographical literature underlines the fact that 
most patients need reassurance and human contact in the traumatic drama of entry to hospital (10). But Goffman has shown us that the institutional roles offered to patients in this situation tend to be limited (11). Some obvious ones are those of 'good' and 'bad' patient, naughty child, etc. These roles emphasise dependency and play down the responsible adult part of the patient.

Another way of doing this and colluding with what Reich calls the Catch 22 quality of psychiatric diagnosis ('Perhaps the most remarkable property of diagnosis, and sometimes, for the diagnosed patient, the most enraging, is its capacity for inevitable selfconfirmation' (12)) is to neglect to give the patient information about the diagnosis that is couched in terms that are intelligible to him or her. Without such knowledge the patient cannot challenge, question, or agree with the way his or her problem is conceptualised. There may inevitably be times when the patient is too disturbed or confused to understand but it is only too easy for the 'set' of the caretakers to influence them to miss the moment when such communication would be possible. Such seems to be one moral that can be drawn from the experience of Rosenhan and his normal associates in mental hospitals in the USA (13). Everything that was said and done by these men was interpreted in terms of the prevailing beliefs about schizophrenia.

The mental patient is often placed in a situation that is similar in important respects to that of the convicted criminal. However, the criminal does at least know why and for how long he has been sentenced. The mental patient in this country has no right to know the diagnosis. The judgement of how much to tell is up to the individual doctor. However, Britain does subscribe to the 1977 Code of Ethics drawn up by the World Psychiatric Association. Article 4 states:

'The psychiatrist should inform the patient of the nature of the condition, of the proposed diagnostic and therapeutic procedures, including possible alternatives, and of the prognosis. This information must be offered in a considerate way and the patient be given the opportunity to choose between appropriate and available methods' (14).

The positive function of the diagnosis as far as the patient is concerned is that it can give him or her a conceptual scheme or a way of looking at and making sense of a number of worrying or unusual experiences. It can satisfy his cognitive needs. It gives reassurance that others have suffered in the same way thus reducing the patient's isolation. In addition, the acceptance of this framework may provide a route out of the particular pain or suffering that is concomitant on this state of mind. Given those negative functions of diagnosis, some of which we have already touched on viz exclusion, dehumanisation, self-confirming hypothesis, discreditation, and punishment (15), it does seem only reasonable to give the patient some elementary lessons in the language of 'committal'. $\stackrel{\square}{\complement}$ Another metaphor that comes to mind is that of loss of $\underset{+}{+}$ virginity: the diagnosed person can never regain his $\overline{\bar{\sigma}}$. previous innocence either in his own mind or in that of others.

Let us assume, momentarily, that there is some $\frac{\text { की }}{0}$ justification for the harmful effects of diagnosis, ie that $\frac{\mathrm{C}}{\mathrm{O}}$ 'society' is justified in doing what it thinks is best for $\overline{\frac{\omega}{\omega}}$. people who can be diagnosed legitimately as being $\underset{\mathbb{\phi}}{\overparen{D}}$ mentally ill. The reason that might be given for this 응 action is that the prospective patient is not fully himself $\mathrm{o}$ or herself. It can be argued that this diminishment of $\overrightarrow{0}$ selfhood justifies the noxious psychiatric measures $\overrightarrow{-}$ used against the patient. Even assuming this to be true $\vec{\sigma}$ it can in fact also be argued that just because it is

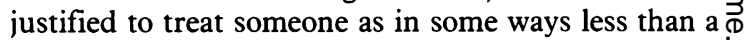
person, so much more is it important (as an antidote) to $\overrightarrow{-}$ treat the person as a person when we are also seeing $\omega$ him or her as behaving as less than a person. We do not $\vec{\omega}$ teach politeness by being rude to rude people.

The suggestion that is central to this paper is that no음 type of therapeutic alliance can get off the ground $\vec{\sim}$ unless the person in the dependent role is given access $\mathbb{D}$ to the language of the would-be helper. This is crucial $\underset{\mathbb{D}}{\circ}$ with respect to the psychiatric initiate. If he or she $\frac{\mathbb{D}}{3}$ knows and understands the language access is immediate to books, chat-shows, comparing notes $\overrightarrow{.}$ with fellow-sufferers, etc. If the psychiatrist takes tie $\mathscr{C}_{\infty}$ patient sufficiently seriously to share relevant. knowledge and discuss things with him or her (and nêेt? just with relatives) there is an implication that diagnosis is being used in the interests of the patient. The more the diagnosis remains the property of the powers-that-be (who also mysteriously expect the $\stackrel{\mathbb{Q}}{\mathbb{2}}$ patient to know what it is when applications for jobs are $\overrightarrow{\vec{O}}$ being filled in!) the more likely it is that the patient is $\frac{0}{3}$ being treated as an object and not a person. No one can deny that the autonomy of the patient can be seriouslyọ. impaired at least for a time by illness but the presumption must always be that the intact self is $\overparen{\varnothing}$ inaccessible rather than destroyed (16).

My argument is that psychiatric diagnosis presents an ethical problem even when it is valid. The chiefo reason for this is that such diagnosis may have positive $₹$ consequences for the patient but will also have negative? consequences. And these negative consequences are $>$ not related to postulated pathological processes but have to do with enshrined social attitudes to mental illness. This is not to deny that undiagnosed mental ${ }^{\text {or }}$ illness may not bring great evils to the persons $\tilde{O}^{\circ}$ concerned. However, diagnosis may bring such evils in $\underset{\omega}{ }$ its train that the patient may correctly judge that the 0 benefits of the ritual are far outweighed by theo disbenefits. It seems only right that the patient should $\Phi$ be given the key to the act that has brought about this? ${ }^{\text {? }}$ state of affairs (or other more desirable states of affairs) viz that the patient should normally have the right to know and discuss his or her diagnosis and related $\stackrel{D}{\circ}$ information.

Emma Shackle MPhil is a part-time Religious Education 
teacher who writes and lectures in the area of psychology of religion. Her address is 19 Durham Road, London N2 9DP.

\section{References}

(1) Reich W. Psychiatric diagnosis as an ethical problem. In: Bloch S, Chodoff P, eds. Psychiatric ethics. Oxford University Press, 1981: 61-88.

(2) Balint M. The doctor, his patient, and the illness. New York: International Universities Press, 1957.

(3) Scheff T. Being mentally ill: a sociological theory. Chicago: Aldine, 1966.

(4) Levene H I. Acute schizophrenia; clinical effects of the labelling process. Archives of general psychiatry 1971; 25: 215-222.

(5) Muller-Hegemann D. Psychotherapy in the German Democratic Republic. In: Kiev A, ed. Psychiatry in the communist world. New York Science House, 1968: 5170 .

(6) Ingleby D, ed. Critical psychiatry. London: Penguin Books, 1981.

(7) Baruch G, Treacher A. Psychiatry observed. London: Routledge \& Kegan Paul, 1978.

(8) Clare A. Psychiatry in dissent. (2nd ed) London: Tavistock, 1980: 76-117.

(9) See reference (1): 77-81.

(10) Coate M. Beyond all reason. London: Constable, 1964: 181.

(11) Goffman, E. Asylums. New York: Doubleday, 1981: 125-169.

(12) See reference (1): 81 .

(13) Rosenhan D I. On being sane in insane places. Science 1973; 179: 250-258.

(14) See reference (1): 350-352.

(15) See reference (1): 77-84.

(16) Sacks O W. Awakenings. Harmondsworth: Pelican Books, 1976.

\section{Update}

\section{New nursing ethical committee}

A new ethics group, The North Wales Nursing Ethical Committee, lists its aims and objectives as:

1) To advise, review and monitor ethical issues in nursing research in North Wales.

2) To advise, review and monitor ethical issues related to nursing and nurses in North Wales.

3) To advise, review and monitor ethical issues related to nursing and the nurse's role within the wider concept of health-care delivery.

4) To advise and explore ways in which nurses could be supported when faced with ethical dilemmas in health care.
5) To advise, review and monitor the educational input of ethics in nurse educational programmes.

6) To advise, review and monitor the patient's or client's role and view when faced with health-care decisions, particularly those related to nursing.

7) To encourage the development and review the resources on the subject of ethics, particularly the updating of a relevant bibliography.

8) To demonstrate to the community in North Wales that nursing has a facility for critically examining ethical issues related to nursing and client health-care.

9) To establish links with other relevant ethical committees, particularly the medical committees in North Wales.

10) To advise the health authorities in North Wales and relevant nursing and midwifery committees on ethical matters relating to nursing and nursing research. 